\title{
Role of procalcitonin and granulocyte colony stimulating factor in the early prediction of infected necrosis in severe acute pancreatitis
}

\author{
C A Müller, W Uhl, G Printzen, B Gloor, H Bischofberger, O Tcholakov, M W Büchler
}

\begin{abstract}
Background-Infected pancreatic necrosis (IPN) is the main cause of death in patients with severe acute pancreatitis. Therefore an early prediction of IPN is of utmost importance.

Aim-Analysis of new blood variables as potential early predictors to differentiate between IPN and sterile pancreatic necrosis (SPN).

Patients-64 consecutive patients with acute pancreatitis were enrolled in this prospective study; 29 were suffering from acute oedematous pancreatitis (AIP), and 35 from necrotising disease (NP) as diagnosed by contrast enhanced computed tomography.
\end{abstract}

Methods-Procalcitonin (PCT) and granulocyte colony stimulating factor (GCSF) in the serum were examined and compared with $\mathrm{C}$ reactive protein (CRP). CRP was measured with a turbidimetric immunoassay (Autokit CRP; Wako, Osaka, Japan), and PCT and G-CSF by ELISA (Lumitest PCT; Brahms Diagnostica, Berlin, Germany; G-CSF-Elisa; R\&D Systems, Abingdon, Oxon, UK). Monitoring was performed daily and related to the onset of symptoms.

Results-Within the first week, all three variables (CRP, PCT, and G-CSF) were significantly higher in patients with NP than in those with AIP (CRP, p<0.001; G-CSF, p<0.001; PCT, p<0.001). During the course of the study, 12 of the 35 patients with NP developed late IPN after a median of 20.5 (range 3-49) days. Neither the peak nor the lowest concentrations during the monitoring period were of any value for predicting IPN (median peak values in SPN $v$ IPN: PCT, $0.93 v 1.93$ ng/ml; G-CSF, $347 v 421 \mathrm{pg} / \mathrm{ml}$; CRP, 270 v $325 \mathrm{mg} / \mathrm{l})$.

Conclusions-Serum PCT, G-CSF, and CRP concentrations are of similar value for early differentiation between mild and severe acute pancreatitis. However, these variables are not suitable for the early prediction of IPN.

(Gut 2000;46:233-238)

Keywords: pancreatitis; procalcitonin; granulocyte colony stimulating factor; $\mathrm{C}$ reactive protein; infected pancreatic necrosis; prognosis

The morbidity and mortality of severe acute pancreatitis are still distressingly high. ${ }^{1-4}$ Its natural course advances in two phases. The first phase (during the first two weeks after onset) is characterised by the liberation of vasoactive and toxic mediators induced by the inflammatory necrotising process, summarised as systemic inflammatory response syndrome. ${ }^{56}$ In some patients the disease progresses to a second phase (during the third week and beyond) which is dominated by infection of pancreatic necrosis with septic complications, leading to septic multiple organ systemic failure. ${ }^{7}$ In the natural course of severe acute pancreatitis, the infection rate of pancreatic necrosis reported in the literature is $40-70 \% .^{8-11}$ Until now, ultrasound or computed tomography guided fine needle puncture with aspiration has been the diagnostic procedure of choice to prove or exclude infection in patients with clinical suspicion of infected pancreatic or peripancreatic tissue. Early diagnosis and urgent operative intervention once the diagnosis is established are crucial in order to improve survival and decrease morbidity in patients with infected pancreatic necrosis (IPN). ${ }^{12}$ At the moment, there is no invasive method, scoring system, or biochemical variable capable of differentiating between sterile pancreatic necrosis (SPN) and IPN at an early stage.

Procalcitonin (PCT), a 116 amino acid propeptide of calcitonin, has recently been shown to be effective in differentiating between different septic states on the basis of bacterial infection and non-bacterial systemic inflammatory response syndrome..$^{1314}$ This finding makes it a promising factor for the early prediction of bacterial infection in pancreatic necrosis in the course of severe acute pancreatitis. Granulocyte colony stimulating factor (G-CSF) is a 204-207 amino acid nonglycosylated protein with a molecular mass of $19 \mathrm{kDa}$, which is synthesised in monocytes, macrophages, bone marrow stem cells, as well as in fibroblasts. The factor stimulates bone marrow stem cell differentiation and acts on differentiated granulocytes and macrophages to enhance phagocytosis and killing of bacteria..$^{16}$ Both a lack of and an increase in these factors in severe acute pancreatitis may promote bacterial invasion of the pancreatic necrosis. To study this promising and interesting thesis, we examined these two factors as possible serum markers for the early prediction

Abbreviations used in this paper: IPN, infected pancreatic necrosis; SPN, sterile pancreatic necrosis; AIP, acute oedematous pancreatitis; NP, necrotising pancreatitis; PCT, procalcitonin; G-CSF, granulocyte colony stimulating factor; $\mathrm{CRP}, \mathrm{C}$ reactive protein.
Accepted for publication 16 September 1999 
Table 1 Characteristics of 64 patients with acute pancreatitis

\begin{tabular}{|c|c|c|c|c|c|}
\hline Characteristic & Total $(n=64)$ & $\begin{array}{l}\text { Acute oedematous } \\
\text { pancreatitis }(n=24)\end{array}$ & $\begin{array}{l}\text { Acute necrotising } \\
\text { panceatitis }(n=35)\end{array}$ & $\begin{array}{l}\text { Sterile pancreatis } \\
\text { necrosis }(n=23)\end{array}$ & $\begin{array}{l}\text { Infected pancreatis } \\
\text { necrosis }(n=12)\end{array}$ \\
\hline Age (years) & $56.3(27-87)$ & $(27-86)$ & $58.8(28-87)$ & $59.8(28-87)$ & $56.9(40-73)$ \\
\hline No of men & $39 \quad(55)$ & $(62)$ & $21 \quad 60$ & 12 (52) & $9 \quad(75)$ \\
\hline No of women & $25 \quad(45)$ & (38) & $14 \quad(40)$ & 11 & 3 (25) \\
\hline \multicolumn{6}{|l|}{ Cause } \\
\hline Biliary & (53) & (52) & (54) & $(48)$ & (67) \\
\hline Alcohol & $24 \quad(38)$ & (41) & 12 (34) & 8 (35) & (33) \\
\hline Other & $6 \quad(9)$ & $2(7)$ & $4 \quad(12)$ & $4 \quad(17)$ & 0 \\
\hline Apache II score & $12.5(1-25)$ & $9.9(1-17)$ & $14.7(5-25)$ & $14.6(5-25)$ & $14.9(8-22)$ \\
\hline Ranson score & $3(0-6)$ & $2(0-6)$ & $4.1(0-9)$ & $3.7(0-8)$ & $4.6(0-9)$ \\
\hline \multicolumn{6}{|l|}{ Operations } \\
\hline $\mathrm{NE}$ & 12 (19) & 0 & (34) & 0 & $(100)$ \\
\hline CCE & $17 \quad(27)$ & (17) & 12 (34) & (21) & (58) \\
\hline LCE & $17 \quad(27)$ & (45) & (11) & (17) & 0 \\
\hline Complications ${ }^{\star}$ & $22 \quad(34)$ & (7) & (57) & (52) & $(66)$ \\
\hline Cardiocirculatory & 9 & 1 & 8 & 2 & 6 \\
\hline Pulmonary & 13 & 1 & 12 & 9 & 3 \\
\hline Renal & 4 & 0 & 4 & 1 & 3 \\
\hline MOSF & 5 & 0 & 5 & 0 & 5 \\
\hline Mortality & $2 \quad(3)$ & 0 & $2 \quad(6)$ & 0 & $(16)$ \\
\hline
\end{tabular}

Values in parentheses are either ranges or percentages.

${ }^{\star}$ Cardiocirculatory insufficiency, requirement for catecholamines to maintain the blood pressure; pulmonary insufficiency, $\mathrm{PaO}_{2}<60$ $\mathrm{mm} \mathrm{Hg}$; renal insufficiency, creatinine $>250 \mu \mathrm{mol} / \mathrm{l}$.

$\mathrm{NE}$, necrosectomy and postoperative closed continuous lavage of the retroperitoneum; CCE, open cholecystectomy; LCE, laparoscopic cholecystectomy; MOSF, multiple organ systemic failure.

of IPN and compared the results with those for the acute phase protein, $\mathrm{C}$ reactive protein $(\mathrm{CRP}) \cdot{ }^{17-20}$

\section{Materials and methods}

PATIENTS

The study was approved by the ethics committee of the University of Bern. After written informed consent, patients were enrolled. A total of 64 consecutive patients with acute pancreatitis were analysed ( 39 men and 25 women with a mean age of 56.3 (range 27-87) years, and a mean Apache II and Ranson score of 12.5 (range 1-25) and 3 (range 0-6) respectively). The cause was gallstones in 34 , alcohol abuse in 24, and other factors in six (table 1). Acute pancreatitis was diagnosed by acute upper abdominal pain, elevated serum amylase and/or serum lipase concentrations (more than three times the upper reference values), and contrast enhanced computed tomography. According to the computed tomography findings, patients were grouped into 29 with acute oedematous pancreatitis (AIP) and 35 with necrotising pancreatitis (NP) (table 2). Of the latter, 23 had the sterile form (SPN) and 12 developed the infected form (IPN) within a median of 20.5 (range 3-49) days, as shown by ultrasound or computed tomography guided fine needle puncture with aspiration or during surgery. All patients with computed tomography proved necrosis received intravenous antibiotic treatment with imipenem/cilastatin $4 \times$ $500 \mathrm{mg}$ a day for at least 14 days.

Table 2 Computed tomography findings and presence of infected pancreatic necrosis

\begin{tabular}{lll}
\hline & $\begin{array}{l}\text { Computed } \\
\text { tomography } \\
\text { findings }(n=64)\end{array}$ & $\begin{array}{l}\text { Infected pancreatic } \\
\text { necrosis }(n=12)\end{array}$ \\
\hline Oedema & $13(20)$ & \\
Oedema plus exudation & $16(25)$ & \\
Necrosis & & \\
$\leqslant 30 \%$ & $15(23)$ & 0 \\
$\leqslant 50 \%$ & $7(11)$ & 0 \\
$>50 \%$ & $13(20)$ & $12 / 12(100)$ \\
\hline
\end{tabular}

Values in parentheses are percentages.
MONITORING

Blood samples were taken daily from day 0 until day 14 after the onset of symptoms (which was assessed by the history of the patient at hospital admission) and thereafter every third day. The blood serum was immediately centrifuged and stored at $-80^{\circ} \mathrm{C}$ until further analysis.

\section{METHODS}

CRP was measured in $\mathrm{mg} / \mathrm{l}$ (reference concentration $<8 \mathrm{mg} / \mathrm{l}$; within-run and day-to-day precision $1.3 \%$ and $6 \%$ respectively) with a turbidimetric immunoassay (Autokit CRP) from Wako, Osaka, Japan. For determination of PCT and G-CSF, an enzyme linked immunoassay (ELISA) technique was applied. PCT was measured in $\mathrm{ng} / \mathrm{ml}$ (reference concentration $<0.5 \mathrm{ng} / 1$; within-run and day-to-day precision $<14 \%$ and $14 \%$ respectively) with the Lumitest PCT from Brahms Diagnostica, Berlin, Germany, and G-CSF in pg/ml (reference concentration $<39 \mathrm{pg} / \mathrm{ml}$; within-run and dayto-day precision $2.8 \%$ and $4.1 \%$ respectively) with a G-CSF-Elisa from R\&D Systems, Abingdon, Oxon, UK.

\section{STATISTICAL ANALYSIS}

Medians and quartile ranges of the factors studied were calculated. The Mann-Whitney U test, a non-parametric test for two independent samples, and the $\chi^{2}$ test for qualitative characteristics were used. Correlations were tested with Spearman's non-parametric correlation test. The cut off concentrations, sensitivities, and specificities for predicting IPN were evaluated by receiver operating characteristics curve analysis. The area under the curve describes the accuracy of the test, with 1 indicating $100 \%$ sensitivity and $100 \%$ specificity and 0.5 being of no discriminatory value. Box and whisker plots combined with dot plots were used to present medians, ranges, and distribution of concentrations. $\mathrm{p}<0.05$ was considered statistically significant. 


\section{Results}

PATIENTS

All 29 patients with AIP had an uneventful course. Two suffered from a single organ failure resulting in a complication rate of $7 \%$. In 18 , cholecystectomy was performed during the same hospital stay after symptoms of acute pancreatitis had subsided. In three patients with chronic pancreatitis, a duodenumpreserving pancreatic head resection was performed after recovery from the acute episode.

In the 35 patients with NP, different extents of pancreatic necrosis were found according to the computed tomography findings (table 2). Twelve developed IPN within a median of 20.5 (range 3-49) days, as shown by ultrasound or computed tomography guided fine needle puncture with aspiration or during surgery. The following bacteria were found in the cultures: Staphylococcus aureus $(\mathrm{n}=6)$, Candida albicans $(\mathrm{n}=4)$, Escherichia coli $(\mathrm{n}=3)$, Klebsiella $\operatorname{spp}(\mathrm{n}=3)$, Enterococcus $(\mathrm{n}=2)$, Pseudomonas aeruguinosa $(\mathrm{n}=3)$ and Streptococcus anginosus $(\mathrm{n}=1)$; in seven cases a monoculture was found and in five a polymicrobial spectrum. In all 12 patients, necrosectomy and postoperative closed continuous lavage of the retroperitoneum was carried out for a median of $54(14-124)$ days. Twenty of the 35 patients had circulatory, renal, and/or pulmonary complications: 12 of the 23 with SPN and eight of the 12 with IPN. In five patients with IPN, two of whom died, multiple organ systemic failure occurred (table 1).
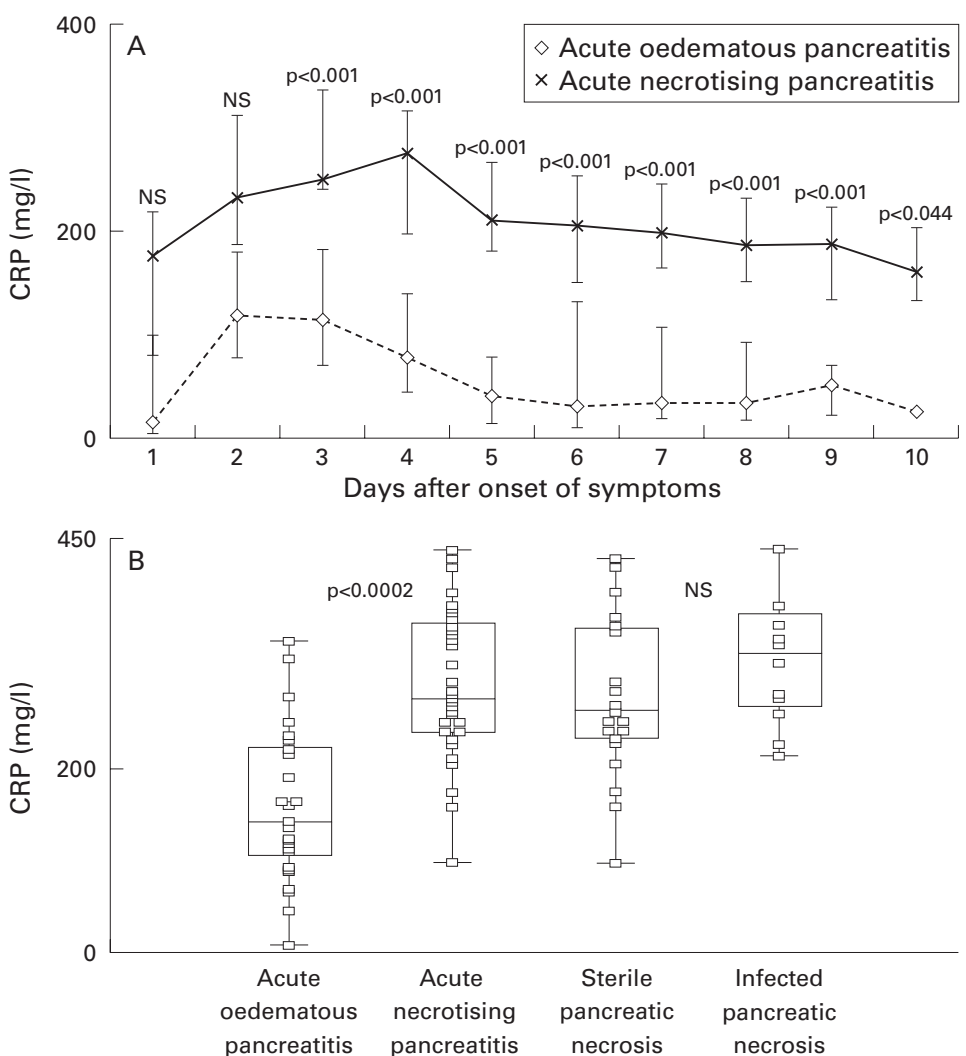

Figure 1 Median concentrations and quartile ranges for $C$ reactive protein (CRP). (A) Acute oedematous pancreatitis compared with acute necrotising pancreatitis;

(B) median peak values and ranges in patients with acute oedematous pancreatitis or acute necrotising pancreatitis and sterile pancreatic necrosis or infected pancreatic necrosis.
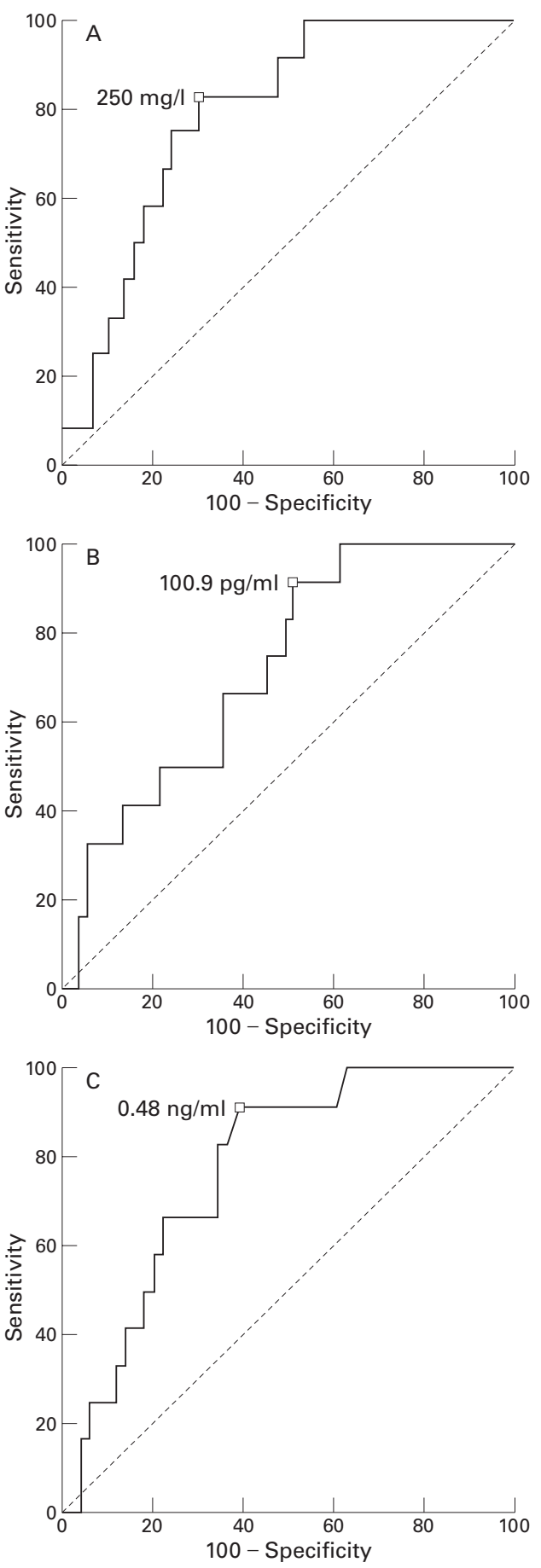

Figure 2 Receiver operating characteristics curves for (A) C reactive protein $(C R P),(B)$ granulocyte colony stimulating factor (G-CSF), and $(C)$ procalcitonin (PCT). For CRP (A), the cut off was $>250 \mathrm{mg} / \mathrm{l}$, sensitivity $83.3 \%$, specificity $70 \%$, and area under the curve 0.793; for G-CSF (B), the cut off was $>100.9 \mathrm{pg} / \mathrm{l}$, sensitivity $91.7 \%$, specificity $48 \%$, and area under the curve 0.718; for PCT (C), the cut off was $>0.48 \mathrm{ng} / \mathrm{l}$, sensitivity $91.7 \%$, specificity $61.2 \%$, and area under the curve 0.774 .

CRP

Median daily concentrations of serum CRP were significantly different in patients with AIP from those with NP 48 hours after the onset of symptoms. Figure 1 presents the median concentrations up to day 10 . The highest concentrations occurred after two days and 

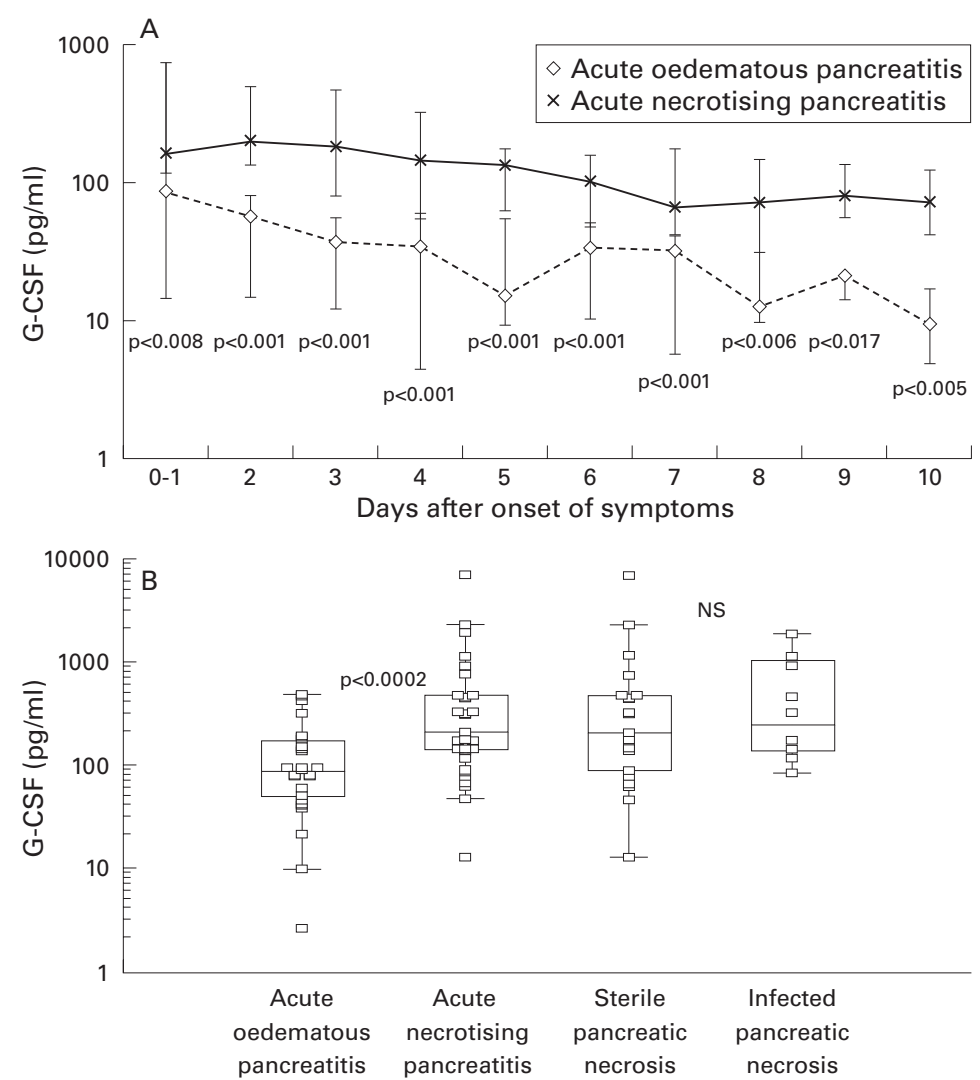

Figure 3 Median concentrations and quartile ranges for granulocyte colony stimulating factor $(G-C S F)$. (A) Acute oedematous pancreatitis compared with acute necrotising pancreatitis; (B) median peak values and ranges in patients with acute oedematous pancreatitis or acute necrotising pancreatitis and sterile pancreatic necrosis or infected pancreatic necrosis. nificant difference between the sterile and infected pancreatic necrosis. According to receiver operating characteristics curve analysis, the cut off concentration for the prediction of IPN for G-CSF was $100.9 \mathrm{pg} / \mathrm{ml}$ with a sensitivity and specificity of $91.7 \%$ and $48.0 \%$ respectively. The area under the curve was 0.718 (fig 2B).

In addition to the peaks, the median lowest values for G-CSF were analysed: for AIP (median and quartile ranges, $3.8 \mathrm{pg} / \mathrm{ml}$ and $1.2-6.1 \mathrm{pg} / \mathrm{ml}), \mathrm{NP}(39.3 \mathrm{pg} / \mathrm{ml}$ and $2.6-73.3$ $\mathrm{pg} / \mathrm{ml})$, SPN $(12.7 \mathrm{pg} / \mathrm{ml}$ and $2.2-47.2 \mathrm{pg} / \mathrm{ml})$, and IPN (43.6 pg/ml and $5.3-78.2 \mathrm{pg} / \mathrm{ml}$ ). There was a difference between the values for patients with AIP and those with NP $(p<0.0027)$, but, as for the peak values, no statistical difference between those with SPN and those with IPN was found.

PCT

Figure 4A gives the medians and quartile ranges for PCT. A highly significant difference was found between AIP and NP within the first 48 hours until day 8 . The median peak concentration in patients suffering from AIP was $0.26 \mathrm{ng} / \mathrm{ml}$ (quartile ranges $0.20-0.37$ $\mathrm{ng} / \mathrm{ml}$ ). Two patients had very elevated peak concentrations of 7.3 and $3.1 \mathrm{ng} / \mathrm{ml}$. The former also suffered from acute cholecystitis/ cholangitis as a concomitant disease, with elevated liver enzyme activities (aspartate aminotransferase, $552 \mathrm{U} / 1$; alanine aminotransferase, $350 \mathrm{U} / 1 ; \gamma$-glutamyltransferase, $257 \mathrm{U} / 1$; alkaline phosphatase, $132 \mathrm{U} / 1)$. The patient with a concentration of $3.1 \mathrm{ng} / \mathrm{ml}$ had no attendant clinical symptoms or laboratory abnormalities indicating an acute infection. The patients with NP exhibited a median PCT peak value of $0.93 \mathrm{ng} / \mathrm{ml}$ with quartile range of $0.47-3.64 \mathrm{ng} / \mathrm{ml}$ (fig 4B). Although the IPN subgroup showed a higher median peak value of $1.43 \mathrm{ng} / \mathrm{ml}$ (quartile range $0.52-4.33 \mathrm{ng} / \mathrm{ml}$ ) than the SPN subgroup with $0.76 \mathrm{ng} / \mathrm{ml}$ (quartile range $0.44-3.64 \mathrm{ng} / \mathrm{ml}$ ), this difference did not reach significance. Among the patients with $\mathrm{NP}$, there were also two with greatly elevated PCT concentrations. The first, with 96.90 $\mathrm{ng} / \mathrm{ml}$, suffered from chronic cholecystitis as a concomitant disease but did not have elevated liver aminotransferase concentrations. The second, with $63.90 \mathrm{ng} / \mathrm{ml}$, suffered from an acute suppurative cholecystitis and sevenfold elevated liver enzyme activities and fourfold elevated total bilirubin concentration.

As shown in fig $4 \mathrm{~B}$, a difference was noted between the median peak values in AIP and NP $(p<0.0002)$. However, there was no significant difference between the median peak values in IPN and SPN. According to receiver operating characteristics curve analysis, the cut off concentration for the prediction of IPN for PCT was $0.45 \mathrm{ng} / \mathrm{ml}$, with a sensitivity and specificity of $91.7 \%$ and $65.3 \%$ respectively. The area under the curve was 0.774 (fig 2C).

\section{CORRELATIONS}

According to Spearman's non-parametric correlation test, a significant $(\mathrm{p}<0.01)$ correlation was shown in all variable couples, with the 

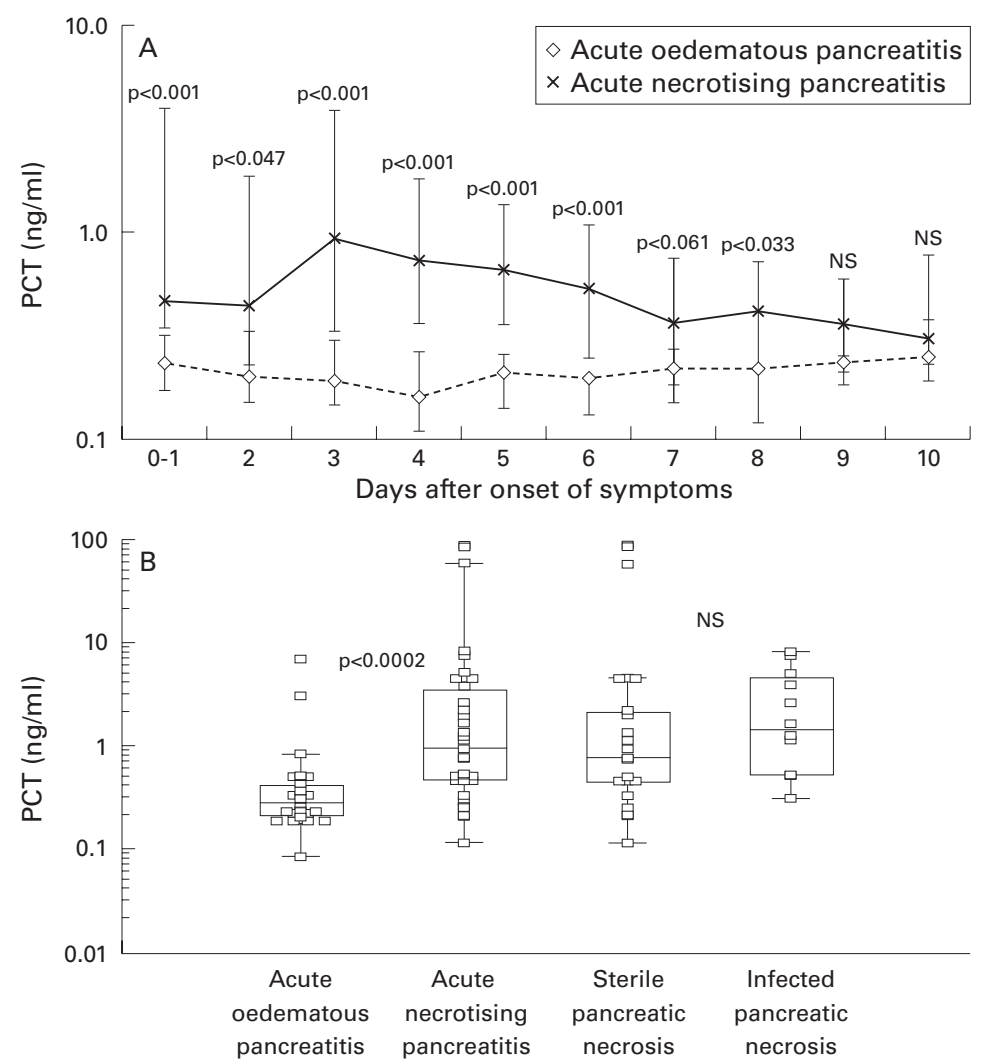

Figure 4 Median values and quartile ranges for procalcitonin (PCT). (A) Acute oedematous pancreatitis compared with acute necrotising pancreatitis; (B) median peak values and ranges in patients with acute oedematous pancreatitis or acute necrotising pancreatitis and sterile pancreatic necrosis or infected pancreatic necrosis.

strongest correlation between CRP $v$ G-CSF $(\mathrm{CRP} v \mathrm{G}-\mathrm{CSF}=0.648, \mathrm{G}-\mathrm{CSF} \approx \mathrm{PCT}=$ 0.457 , and CRP $v$ PCT $=0.434)$.

\section{Discussion}

Despite antibiotic treatment, ${ }^{21-24}$ microbiological infection of pancreatic necrosis may occur in every third patient with severe acute pancreatitis. $^{811}$ Septic multiple organ systemic failure is the cause in $80 \%$ of all deaths from this disease. ${ }^{925}$ Therefore it is of utmost importance to find a non-invasive marker for early prediction of IPN. In this prospective trial, we comparatively investigated PCT, which has been shown to differentiate between non-bacterial and bacterial sepsis, ${ }^{13}{ }^{14}$ G-CSF, which has recently been shown to reduce bacterial translocation into the pancreas in a pancreatitis induced dog model, ${ }^{26}$ and CRP. ${ }^{17-20}$

In this study, PCT and G-CSF concentration are both shown to be valuable variables for differentiating between oedematous and necrotising acute pancreatitis within the first 24 hours of the onset of symptoms, in comparison with CRP, which will differentiate between the different forms of the disease after 48 hours at the earliest. However, although the initial concentrations of PCT and G-CSF were increased in IPN compared with SPN, neither the peak nor the base concentrations were of any predictive value for the early prediction of IPN.

CRP in acute pancreatitis has been extensively investigated by various researchers. It has been established as an important serum marker for evaluation of infectious disease and so far represents the ideal for indicating pancreatic necrosis in acute pancreatitis. In this study, serum CRP concentration was used as the control variable for pancreatic necrosis, against which serum PCT and G-CSF concentrations were compared. Our results for CRP correspond closely to those in the literature. ${ }^{17-20}$

G-CSF concentrations associated with acute pancreatitis are rarely referred to in the literature. The most important publication was presented by a group from Chicago. Rao and colleagues $^{26}$ studied G-CSF treatment of acute pancreatitis induced in dogs. They noted a significant increase in white blood cells and significantly lower bacterial translocation into the pancreas, liver, spleen, peritoneal fluid, and blood in dogs receiving G-CSF. The translocation into the mesenteric lymph nodes and bacterial population was not involved. These data suggest that low white blood counts and low G-CSF concentrations increase the risk for infection in necrotising pancreatitis. According to our findings, patients who developed IPN had neither lower G-CSF concentrations nor lower white blood cell count than those with SPN. On the contrary, a slight but insignificant increase in G-CSF was found in IPN compared with SPN. Patients with IPN may have produced more G-CSF and white blood cells at the beginning of the disease but were exhausted earlier during the course of the disease. Finally, according to our data, serum G-CSF concentration is not a useful marker for differentiating between IPN and SPN, but treatment with G-CSF in cases of severe acute pancreatitis, especially as an additional tool for preventing IPN, may be of benefit. To confirm this, more investigations of G-CSF in severe acute pancreatitis are necessary.

Similarly, there are only few publications dealing with PCT in acute pancreatitis. ${ }^{27-30}$ In a population of 26 patients, Brunkhorst and colleagues $^{27}$ found a significant difference between patients with biliary acute pancreatitis and those with other aetiology. Therefore the authors recommended PCT as a marker for differentiation between acute pancreatitis induced by gallstones and that induced by other factors. They reported the highest PCT concentrations in patients with concomitant cholangitis. In this study, we also found the highest serum PCT concentrations in patients with acute pancreatitis of biliary origin and concomitant inflammatory disease of the biliary tract or the gall bladder: one patient with chronic cholecystitis $(96.9 \mathrm{ng} / \mathrm{ml})$ and another suffering from an acute suppurative cholecystitis $(63.9 \mathrm{ng} / \mathrm{ml})$. It seems likely that patients with acute pancreatitis of biliary origin combined with an inflammatory disease of the gall bladder or biliary tract have higher PCT concentrations. However, in this study no significant difference in serum PCT concentration was found in patients with acute pancreatitis of biliary and other origin. Bertsch and co-workers ${ }^{28}$ examined PCT concentrations in a rather small population of seven patients with AIP and eight patients with NP. They found no difference between these two groups because of 
a pronounced variation in the values among the patients with NP. They did not differentiate between IPN and SPN. Oezcueruemez-Porsch and colleagues ${ }^{29}$ studied serum PCT concentrations in the early phase of acute pancreatitis that developed after endoscopic retrograde cholangiopancreatography. They observed a significant increase in PCT after 24 hours; the peak values did not surpass the reference value for healthy people $(0.5 \mathrm{ng} / \mathrm{ml})$ in accordance with the clinical course of the patients who suffered only from mild disease without systemic organ complications. Rau and colleagues ${ }^{30}$ investigated serum PCT concentration in a population of 50 patients divided into three groups: 18 patients with AIP, 14 patients with SPN, and 18 patients who developed IPN after a median of 13.5 days after the onset of pain. These authors found a significant $(\mathrm{p}<0.0001)$ difference between the SPN and IPN group, with a cut off concentration of $>1.8 \mathrm{ng} / \mathrm{ml}$ and a sensitivity and specificity of $94 \%$ and $90 \%$ respectively. These results are contradictory to ours, and the following explanations can be put forward. (a) There was an appreciably earlier occurrence of infection in the previous study (median 13.5 days compared with 20.5 days in this study). (b) Therapeutical management was different, with different antibiotic treatment (antibiotic treatment with either ofloxacin/ metronidazole or imipenem/cilastatin compared with imipenem/cilastatin for all cases of pancreatic necrosis in this investigation). (c) There were different indications for operation, especially the operative approach for patients with SPN. Eleven of 22 patients with SPN received an operation in the Rau study. Of these 11 , eight developed secondary IPN after the operation and were analysed in the IPN group. In our investigation, however, all patients with SPN were treated conservatively and no patient was "switched" from the SPN group to the IPN group. (d) There were different patient compositions with respect to the severity of the disease; in the Rau study there were more severe than mild cases ( 32 severe, 18 mild). The patients with severe disease had an unusually high infection rate of $56 \%(18 / 32)$ (probably because of the high infection rate after surgery; see the point above) compared with 33\% (this study) and also a higher death rate of $34 \%(11 / 32)$ compared with $6 \%$ in our investigation.

Nevertheless, according to this study, serum PCT is potentially a very potent marker for differentiating between oedematous and necrotising acute pancreatitis, and increased PCT concentrations correlated well with systemic inflammatory response syndrome in severe acute pancreatitis. On the other hand, it was of no value in the early prediction of IPN. However, neither the study of Rau and colleagues $^{30}$ nor the present one is numerically large enough, and further investigations are necessary before this marker should be recommended for the early non-invasive assessment of IPN in severe acute pancreatitis.
We are most grateful to Ms Sabine Sebastian for help with the manuscript.

1 Karimgani M, Porter KA, Langevin ER, et al. Prognostic factors in sterile pancreatic necrosis. Gastroenterology factors in sterile

2 Beger HG, Büchler MW, Bittner R, et al. Necrosectomy and postoperative local lavage in necrotizing pancreatitis. $\mathrm{Br} \mathcal{F}$ Surg 1988;75:207-21.

3 Rattner DW, Legermate DA, Lee MJ, et al. Surgical debridement of symptomatic pancreatic necrosis is beneficial irrespective of infection. Am F Surg 1992;163:105-10.

4 Starr MH, Nagorney DM, Much P, et al. Acute necrotizing pancreatitis: management by planned, staged pancreatic necrosectomy/debridement and delayed primary wound closure over drains. Br f Surg 1991;78:576-81.

5 Büchler M, Malfertheiner P, Schädlich H, et al. Role of phospholipase A2 in human acute pancreatitis. Gastroenterology 1989;97:1521-6.

6 Beger H, Bittner R, Büchler MW, et al. Hemodynamic data pattern in patients with acute pancreatitis. Gastroenterology 1986;90:74-9.

7 Beger HG, Bittner R, Block S, et al. Bacterial contamination of pancreatic necrosis. A prospective study. Gastroenterology 1986;91:433-8.

8 Gerzof SG, Banks PA, Robbins AH, et al. Early diagnosis of pancreatic infection by computed tomography-guided paspiration. Gastroenterology 1987;93:1315-20.

9 Beger HG, Bittner R, Block S, et al. Bacterial contamination of pancreatic necrosis. A prospective clinical study. Gastroenterology 1986;91:433-8

10 Allardyce BD. Incidence of necrotizing pancreatitis and factors related to mortality. Am F Surg 1987;154:295-9.

11 Bassi C, Falconi M, Girelli E. Microbiological findings in severe pancreatitis. Surgical Research Communications 1989; 5:1-4.

12 Bradley EL, Fuenwider JT. Open treatment of pancreatic abscess. Surgical Gynecology and Obstetrics 1984;159:50913.

13 Al-Nawas B, Krammer I, Shah PM. Procalcitonin in diagnosis of severe infections. European fournal of Medical Research 1996;1:331-3.

14 Assicot M, Gendrel D, Carsin H, et al. High serum procalcitonin concentrations in patients with sepsis and infection. Lancet 1993;341:515-18

15 Wang JM, Chen ZG, Colella S. Chemotactic activity of recombinant G-CSF. Blood 1988;72:1456-60.

16 Tabbara IA. Granulocyte colony-stimulated factor. South Med F 1993;86:350-5.

17 Büchler M, Malfertheiner P, Schoetensack C, et al. Sensitivity of antiproteases, complement factors and C-reactive ity of antiproteases, complement factors and C-reactive
protein in detecting pancreatic necrosis. Results of a prospective clinical study. International fournal of Pancreaprospective clinical study

18 Mayer AD, McMahon MJ, Bowen M, et al. C-reactive protein: an aid to assessment and monitoring of acute pancreatitis. F Clin Pathol 1984;37:207-11.

19 Uhl W, Büchler M, Malfertheiner P, et al. PMN-elastase in comparison with CRP, antiproteases, and $\mathrm{LDH}$ as indicator of necrosis in human acute pancreatitis. Pancreas 1991;6:253-9.

20 Wilson C, Heads A, Shenkin A, et al. C-reactive protein, antiproteases and complement factors as objective markers of severity in acute pancreatitis. Br f Surg 1989;76:177-81.

21 Luiten EJT, Hop WCJ, Lanje JF, et al. Controlled clinical trial of selective decontamination for the treatment of trial of selective decontamination for the treatme

22 Pederzoli P, Bassi C, Vesentini S, et al. A randomized multicenter clinical trial of antibiotic prophylaxis of septic complications in acute necrotizing pancreatitis. Surgical Gynecology and Obstetrics 1993;176:480-3.

23 Saino V, Kemppainen E, Puolakkainen P. Early antibiotic treatment in acute necrotising pancreatitis. Lancet 1995; 346:663-7.

24 Büchler MW, Uhl W, Friess H, et al. Acute pancreatitis: novel concepts in biology and therapy. Oxford: Blackwell Science, 1999.

25 Widdison AL, Karanjia ND. Pancreatic infection complicating acute pancreatitis. Br F Surg 1993;80:148-54.

26 Rao R, Prinz RA, Kazanstev GB, et al. Effects of granulocyte colony-stimulating factor in severe pancreatitis. Surgery 1996;119:657-63.

27 Brunkhorst FM, Forycki ZF, Wagner J. Early identification of biliary pancreatitis with procalcitonin: a new inflammatory parameter. Chirurgische Gastroenterologie 1995; 11 (suppl 2):42-6.

28 Bertsch T, Richter A, Hofheinz H, et al. Procalzitonin: a new marker for the acute-phase reaction in acute pancreatitis. Langenbecks Arch Chir 1997;382:367-72.

29 Oezcueruemez-Porsch M, Kunz D, Hardt PD, et al. Diagnostic relevance of interleukin pattern, acute-phase proteins, and procalcitonin in early phase of post-ERCP proteins, and procalcitonin in early phas

30 Rau B, Steinbach G, Gansauge F, et al. The potential role of procalcitonin and interleukin 8 in the prediction of infected necrosis in acute pancreatitis. Gut 1997;41:832-40. 